\title{
BUCHBESPRECHUNG
}

\section{Protein Structure Function.}

Z. H. Zaidi, A. Abbasi, and D. L. Smith (eds). TWEL Publishers, 31, Milton Rd., Branton, Doncaster, UK (1990); 334 pages, value US \$ 45 + postage. ISBN 969-8117-00-8.

Die Proteinchemie befindet sich derzeit in einem Stadium atemberaubender Forschungstätigkeit. Entwicklungsländer können hierzu nur einen bescheidenen Beitrag leisten. Um so erstaunlicher ist es, daß es Prof. Zaidi vom H.E.J. Research Institute in Karachi gelungen ist, eine Proteingruppe zu etablieren, die ein internationales Symposium in Pakistan mit renommierten Vortragenden abhalten konnte. Die Plenarvorträge sind in dem zitierten Herausgeberband zusammengefaßt.

Das Buch wird eingeleitet durch einen Beitrag von R. F. Doolittle, University of California, La Jolla, USA, über die Evolution von Proteinen. Auf neue Aspekte zur Proteinfaltung wird u.a. in den Übersichten von D. M. Engelman, Yale University, New Haven, S. W. Englander, University of Pennsylvania, Philadelphia, und M. Y. Ali, Rajshahi University, Bangladesh, eingegangen. Eine ganze Reihe von Beiträgen behandelt die gentechnologische Anwendung zum „Protein Engineering “ und „Drug Design“ (L. Graf, L. Eotvos University, Budapest, oder T. Blundell, Birkbeck College, London).

In zahlreichen Artikeln wird auf Struktur-Aktivitätsbeziehungen von Proteinen eingegangen (Fibrin, Ribulose-1,5-biphosphatcarboxylase/
Oxygenase, Dihydrofolatreduktase, Neurotoxine, Histone, Proteinasen usw.), wobei u.a. kinetische Untersuchungen mit Substraten und Röntgenstrukturdaten herangezogen werden.

Insbesondere von den Schulen Zaidi (H.E.J. Research Institute of Chemistry, Karachi) und Braunitzer (Max-Planck-Institut für Biochemie, Martinsried) werden neue Hämoglobinstrukturen von Vögeln vorgestellt und mit denen von Säugern verglichen.

In weiteren Übersichtsartikeln wird die Entwicklung spezifischer Antikörper durch Anwendung von Computervorhersagen antigener Determinanten und peptidchemischen Methoden (W. Voelter, Abteilung für Physikalische Biochemie, Universität Tübingen) und die Wirkung von Plasmaproteinen auf die Thrombocytenaggregation (S. A. Saeed, Aga Khan University, Karachi) behandelt.

Von Interesse sind fernerhin die Beiträge von D. L. Smith (Purdue University, West Lafayette) über neueste massenspektrometrische Methoden zur Strukturaufklärung von Proteinen und A. K. Samadi (Kashan Faculty of Medicine, Kashan) über HPLC-Trennungen von Proteinen.

Der Proteinchemiker erhält wertvolle Anregungen durch gut ausgewählte aktuelle „Topics“ für sein Fachgebiet, wie es von jedem „Proceedings“Band internationaler Symposien erwartet wird.

Wolfgang Voelter, Tübingen

Nachdruck - auch auszugsweise - nur mit schriftlicher Genehmigung des Verlages gestattet Satz und Druck: Allgäuer Zeitungsverlag GmbH, Kempten 